\title{
Afecto no es igual a emoción: el baile social y su significación en la música y el sentimiento de la cultura underground
}

Una aproximación derivada de las restricciones al baile social en espacios públicos en la era COVID-19 Affection is not Equal to Emotion: Social Dance and its Significance in Music and Feeling of Underground Culture An Approach Derived from Restrictions on Social Dance in Public Spaces in COVID-19 Era

Elena Rosillo Doctora en Comunicación Periodista musical Programadora Sala Vesta (Madrid) e.rosillosf@gmail.com

Fecha de recepción: 16/10/2020

Fecha de aceptación: 9/8/2021 

Actualmente, la crisis sanitaria provocada por la COVID-19 ha traído consigo una restricción cultural que resulta chocante, más aún al descubrir que se trata de una prohibición que no se llevaba a cabo en España desde tiempos de la dictadura franquista: se ha prohibido el baile social, entendido este como el desarrollado en espacios públicos o privados (salas de baile, discotecas, salas de conciertos, e incluso fiestas privadas como bodas, comuniones, etc.). Se trata de una directriz que comenzó una vez transcurrido el estado de alarma, en el momento en que comenzaron a desarrollarse las fases de desescalada, incluyendo en estas la de nueva normalidad en la que nos encontramos ${ }^{1}$.

1 El día 21 de junio finalizó el proceso de desescalada y la vigencia del estado de alarma, entrando el país en la etapa de nueva normalidad. En este escenario de control fue preciso adoptar una serie de medidas para seguir haciendo frente a la pandemia y evitar un nuevo incremento de casos. Con este objetivo se aprobó el Real Decreto-ley 21/2020, de 9 de junio, de medidas urgentes de prevención, contención y coordinación para hacer frente a la emergencia sanitaria ocasionada por la COVID-19, donde se establecen las medidas generales de prevención y control que se deben mantener durante esta nueva normalidad.

Asimismo, con el fin de intensificar las medidas de prevención, seguimiento y control de la epidemia y ofrecer una respuesta coordinada del conjunto de Administraciones, el Consejo Interterritorial del Sistema Nacional de Salud aprobó el pasado 16 de julio de 2020 el Plan de respuesta temprana en un escenario de control de la pandemia por COVID-19, en el que se prevé que, al objeto de «reducir al máximo la transmisión del virus, minimizando su impacto en la salud y en la sociedad, las instituciones deben estar preparadas para responder a cualquier escenario de riesgo para la salud pública, asumiendo que es necesaria la coordinación y la toma de decisiones conjunta en función de los diferentes escenarios».

En concreto, se acordaron medidas de control en relación con los locales de ocio (cierre de discotecas, salas de baile y bares de copas), con los establecimientos de hostelería y restauración (previsión de la 1:00 como hora máxima de cierre), respecto a los centros sociosanitarios de carácter residencial (limitación de las visitas a una persona por residente y limitación de las salidas de los residentes, entre otras), en relación con los eventos y actividades multitudinarios, respecto a cribados con PCR en grupos específicos, en relación con el consumo de alcohol no autorizado en la vía pública (previsión de refuerzo de los controles y de aplicación de las sanciones) y el consumo de tabaco y asimilados (prohibición de fumar en la vía pública o espacios al aire libre cuando no se pueda respetar una distancia mínima interpersonal de, al menos, 2 metros). Asimismo, se propusieron tres recomendaciones en la línea de limitar los encuentros sociales 
No es objeto de este texto indagar en la pertinencia de esta directriz. Sin embargo, se considera interesante mirar más allá de la trascendencia legal o sanitaria de esta recomendación para esclarecer en qué medida se trata de una restricción que afecta al desarrollo cultural de una sociedad. En concreto, en el siguiente texto se explica la importancia social y cultural que guarda el baile en relación con el desarrollo de la cultura underground. Una cultura que se ha visto precarizada durante el último año, a consecuencia de la pandemia y de las medidas que, como ya se ha señalado anteriormente, han restringido el encuentro social y el desarrollo de eventos culturales en nuestro país.

La definición del underground se nos escapa de las manos, dada la inmensa cantidad de variables a tener en cuenta. $\mathrm{O}$, mejor dicho, de variables a no tener en cuenta. Una persona de clase socioeconómica alta puede participar de la cultura underground pese a ser eminentemente DIY — o quizás podríamos decir que, gracias a que esa persona se encuentra en una mejor situación económica, puede "permitirse el lujo» de participar en un ambiente DIY dedicando tiempo a ese hágalo usted mismo a la que una persona de clase obrera no tiene tan fácil acceso-. También personas religiosas pueden participar y consumir cultura underground, pese a considerarse una cultura laica — quizás por adjetivos tan en boga como autenticidad, sin intermediarios, incluso hasta podríamos decir eco y vegana, al ser movimientos ligados a la contracultura; valores que pertenecen también al concepto de pureza enmarcado dentro de la religiosidad-. Fernando García Naharro resume estas contradicciones referenciando a su vez al investigador Terry Eagleton:

fuera del grupo de convivencia estable, así como realizar periódicamente pruebas PCR a los trabajadores de los centros sociosanitarios que estuvieran en contacto con residentes. Por último, se recogía una indicación con la finalidad de garantizar los medios y capacidades de los sistemas sanitarios para el cumplimiento de lo previsto en el Plan de Respuesta Temprana.

«BOE» núm. 260, de 1 de octubre de 2020, pp. 83224-83232: https://www.boe.es/buscar/doc. php?id=BOE-A-2020-11590.

Rosillo, Elena (2021). «Afecto no es igual a emoción: el baile social y su significación en la música y el sentimiento de la cultura underground). Monograma. Revista Iberoamericana de Cultura y Pensamiento, n. ${ }^{\circ}$ 9, pp. 211-230. doi: 10.36008/monograma.2021.09.2138. http: revistamonograma.com. ISSN: 2603-5839. 
...como señala Terry Eagleton, en la mayoría de las sociedades modernas no es tan fácil discernir esas brechas culturales, puesto que en gran medida las sociedades occidentales contemporáneas son un agregado de subculturas solapadas en las que no resulta fácil decir exactamente de qué sistema de valores culturales cerrado se desvía una subcultura. (2012: 303)

La lista podría extenderse hasta acabar con la pregunta retórica que cualquier adolescente crecido en los años 90 ha llegado a hacerse alguna vez: ¿Por qué bailan los «niños pijos» la Fiesta pagana $^{2}$ de Mago de $\mathrm{Oz}$, si precisamente es una canción concebida contra los niños pijos, y a favor de la clase obrera? Lo mismo ocurre actualmente con el himno Cayetano $^{3}$ de la joven formación Carolina Durante.

La respuesta es que, paradójicamente, no podemos acotar una cultura a los valores normalmente asociados a la hora de definir una cultura: creencias, lenguas, costumbres, tradiciones y relaciones son, en este caso, irrisorias a la hora de tratar con un término que se desarrolla de manera similar en todas las regiones y nacionalidades, que atraviesa géneros (tanto sexuales como musicales) y razas. A la hora de hablar de cultura underground podemos estar refiriéndonos a la cultura punk ${ }^{4}$, el $s k a^{5}$, la contracultura, el DIY, así como a culturas no-mainstream y tratadas tradicionalmente como marginales, en el caso del flamenco y la copla.

En todo caso, quizás el único filtro que podríamos aplicar sería el de urbe. Las tribus urbanas y las contraculturas de los outsiders (Becker) se desarrollan en un ambiente que permite la

2 Fiesta pagana en Finisterra, Mago de Oz (Locomotiv Music, 2000).

3 Single de Carolina Durante. Cayetano (Sonido Muchacho, 2018).

4 Género musical originado a mediados de los años 70 en EE. UU. y Gran Bretaña. Destaca por melodías cortas, directas y contundentes, mensajes sencillos y un uso de los instrumentos amateur (definición de la autora).

5 Género musical originado durante los años 50 en Jamaica. De fusión de raíces africanas con ritmos de Jamaica. Precursor del reggae (definición de la autora). 
liberalización de la moral y del cuerpo. En una cultura donde el ciudadano gana su anonimato y se permite el lujo de poder cambiar su identidad, dejando de lado el argot tan propio de los pueblos o ciudades pequeñas «tú eres de...», o «tú eres el de...», adjuntando siempre el distintivo familiar. En este sentido, Bruno Lutz referencia a David Le Breton a la hora de estudiar los cambios que produjo la vida en la ciudad en las costumbres sociales. Lutz, de una manera literaria, alude de este modo no solo a los aires aperturistas que podemos encontrar en una gran urbe, sino también a sus limitaciones perceptivas, que también restringen el modo en el que percibimos a los demás:

David Le Breton afirma, con razón, que el desarrollo de la ciudad tuvo una consecuencia significativa sobre los usos y las representaciones sociales. La socialización proxémica de las urbes impuso sus reglas: la de ver sin mirar con el uso masivo de cristales polarizados, la del oír sin escuchar con el ruido de los automóviles, la de oler sin olfatear a causa de la contaminación. El diseño de las ciudades y de los espacios públicos ha provocado una reducción notable de la capacidad de los sentidos para comprender el mundo que nos rodea, limitando nuestras percepciones y apreciaciones de los demás. (2006: 15)

Más allá de la ciudad, o quizás precisamente dentro de esta ciudad conceptual en la que nos encontramos, el hecho de abandonar la burbuja familiar, tanto nuclear — padre, madre, hermano/s- como local — vecinos, conocidos, familiares tangenciales- es la de construir un nuevo personaje o carácter que será definido por nuestros afectos. Unos afectos que se ven representados a través de los productos culturales que consumimos, la estética con la que nos auto representamos y la actitud vital que mantenemos. En este afecto, la música ejerce de hilo conductor al relacionarse los unos con los otros a la hora de compartir «el juicio del gusto», que va más allá de patrones culturales para internarse en la más pura visceralidad. 


\section{La teoría del afecto}

En un trazado histórico de la cultura underground, la clave que permite estudiar una serie de rasgos o de seguir un trazado histórico determinado —-tomando como referencia el ensayo Rastros de carmín (2005) — es la llamada teoría del afecto. Elementos que se escapan del análisis semiótico y sociológico llevándonos a otros que se evaden del campo teórico y se hunden en aspectos físicos y prelingüísticos. Aspectos que, de hecho, enraízan con el concepto de tribu (eso que ahora ha dado en denominarse como tribu urbana) y que no deja de ser un estado emocional de pertenencia y afecto. Para David Le Breton, principal estudioso de la sociología y antropología del cuerpo del hombre moderno: los afectos son reglas que nos transgreden (Le Breton, 2009: 9). Según El tiempo de las tribus (1990), de Maffesoli, este concepto de tribu se cimienta en una extraña contradicción: el sentido de pertenencia, por un lado (a una tribu o pequeña comunidad) y por otro, el nomadismo (no estar anclado a las costumbres tradicionalmente aceptadas, como podría ser el sedentarismo). La investigadora Tania Arce Cortés resume esta dicotomía —al igual que la diferencia entre underground-contracultura, que veremos más adelante- en su estudio Subcultura, contracultura, tribus urbanas y culturas juveniles: ¿homogenización o diferenciación?, centrado en «las posturas que han derivado de la Sociología a través de un recorrido teórico e histórico, así como de sus principales aportes y limitaciones» (Arce-Cortés, 2008). En este texto, la investigadora recoge las consideraciones de Maffesoli respecto al nomadismo y el sentido de pertenencia, que remite nuevamente a las culturas juveniles:

El nomadismo es la posibilidad «de la sublevación, es el salir de sí, es, en el fondo, poner acento en todos los aspectos lúdicos, en los aspectos festivos, en un hedonismo latente, un corporeísmo exarcebado» (Maffesoli, 2004b: 37), mientras el sentido de pertenencia es la «conciencia de sí, no más la identidad cerrada y encerrada en sí misma, sexual, ideológica y profesionalmente 
[...] yo sigo mi propia ley y sí: mi ley es otro quien me la da, quien me la indica» (Maffesoli, 2004b: 38). Tanto el nomadismo como la falta de pertenencia, para Maffesoli son parte de la metáfora del tribalismo. La palabra tribu, para Maffesoli (2004, 2004b), es utilizada para remarcar el aspecto de lo arcaico y de lo bárbaro y, a su vez, la saturación del concepto de individuo. Para Maffesoli (2004, 2004b), los grupos juveniles gustan de un reencuentro con la corporalidad (hedonismo, tatuajes, perforaciones) y la vitalidad, como si fueran niños eternos». (2008: 30)

Vemos en este resumen otros rasgos que ya se han mencionado anteriormente, como el rasgo de la cultura juvenil (o el efecto Peter Pan de las culturas marginales de Becker), así como rasgos antropológicamente tribales como el hecho de tatuarse y modificar el cuerpo para pertenecer a un determinado grupo. El afecto que nos transgrede, va más allá también de las propias fronteras del cuerpo físico, gustando de manipularlo y asemejarse a su familia tribal. Así, un rasgo que durante años — sobre todo, en la etapas de la historia española conocidas como dictadura franquista y la Transición - estuvo vinculado a la criminalidad (cárceles), y antes estuvo asociado a otras «razas nómadas» (por así decirlo), como los marineros, ahora se relaciona intrínsecamente con el mundo de la música y el arte. Los rockeros, sobre todo, no son nada sin sus tatuajes.

El investigador Rodrigo Ganter Solís analiza en su estudio Cuerpos suspendido: cartografías e imaginarios de la piel en jóvenes urbanos, «los procesos de apropiación que experimenta esta práctica a partir de la irrupción de culturas juveniles en las sociedades contemporáneas; los significados y procedimientos asociados a este ritual; y los nexos entre política, estética y modificación corporal» (2005: 1). Dentro de este estudio, volvemos a encontrarnos con una referencia a Maffesoli y su estudio sobre el proceso de «desidentificación»; algo a lo que Ganter-Solís alude a la hora de buscar qué rasgos básicos forman parte del proceso de 
«neotribalización». La conclusión se encuentra en las comunidades emocionales, la energía subterránea, la sociabilidad dispersa y la fisicalidad de la experiencia; unos rasgos a los que se hará referencia en este capítulo. Veámoslo en las palabras de Ganter-Solís:

Emulando a Maffesoli, frente al proceso de «desidentificación» que caracterizan a las sociedades de masa, surge como respuesta, de determinados grupos «neotribales», la necesidad de renuclearse y fortalecer los lazos primarios, donde la función primordial de estos colectivos sería el fortalecer el rol de cada persona al interior de la agrupación. Para Maffesoli, los rasgos básicos del proceso de neotribalización contemporáneo están asociados con los siguientes vectores: Comunidades Emocionales; Energía Subterránea; Sociabilidad Dispersa; y por cierto: Fisicalidad de la Experiencia. (2005: 11)

Esto se representa, según Ganter-Solís, en rituales de pasaje; es decir, de aceptación grupal, que llevan por la separación de la vida infantil y del entorno familiar para incluirse dentro de otro entorno familiar, esta vez elegido, como adulto en plena capacidad de utilización de su cuerpo (de su carne). Una responsabilidad que también transita por el derecho a la modificación de ese cuerpo, que ya no es propiedad de los padres, sino de uno mismo. Un pasaje que también enraíza con las teorías de Feixa a la hora de definir a las subculturas y las culturas juveniles, ya que se refiere a un modo «[...] en que las experiencias sociales de los jóvenes son expresadas colectivamente mediante la construcción de estilos de vida distintivos, localizados en el tiempo libre, o en espacios intersticiales de la vida institucional» (Feixa, 1998: 84), y que nos devuelve, invariablemente, al rock. Volvemos al texto de Ganter-Solís para encontrar en él estas alusiones a la música como hilo conductor vehicular de la ideología o la actitud contracultural: 
Esto último se asocia a la construcción de estilos juveniles, que $[. .$.$] están compuestos por una serie de elementos cultu-$ rales, entre los cuales puede destacarse: primero, el lenguaje, como forma de expresión oral distinta a la de los adultos, pues los jóvenes realizan juegos lingüísticos e inversiones lingüísticas que marcan la diferencia con los otros; en segundo lugar, la música, donde el género del rock se transformó en la primera música generacional, que fue capaz de distinguir a los jóvenes, internalizándose en el imaginario cultural juvenil, y marcando las identidades grupales, producto de su consumo o de la creación; y en tercer lugar, la estética, que potencia la identidad juvenil a través, por ejemplo, del pelo, la ropa, los accesorios, entre otros. [...] Estas producciones cumplen la función de reafirmar las fronteras del grupo y también de promover el diálogo con otras instancias sociales juveniles». (Ganter-Solís, 2005: 12)

Porque, aunque el género rock no es patrimonio de la cultura underground, sí es el que ha brindado desde la época de los 60 del siglo xx hasta hoy, gracias entre otros muchos factores que serían innumerables, al marketing, las revistas, y la pertenencia a una cultura dominadora como es la norteamericana - experta en difundir su historia y propia cultura al exterior-, una estética atractiva y poderosa que se ha erigido como dominante —así como el imperio al que pertenece - sobre el resto de subculturas propias. Es decir, no podríamos mencionar al flamenco más que como subcultura propia del área geográfica de España, puesto que en el resto del mundo su exportación no incluye el sufrimiento del pueblo gitano o su nomadismo, sino simplemente sus características musicales. Sin embargo, exportar el rock de raíz norteamericana es exportar, a su vez, determinadas costumbres, vestimentas, estéticas y actitudes propiamente americanas (así como un modelo de consumo que, como ya hemos visto, es determinante a la hora de definir la contracultura moderna). 
Afecto no es igual a emoción: el baile

El afecto puede entenderse de manera relacional y se manifiesta desde la propia corporalidad: se transmite a través del lenguaje del cuerpo, no a través del discurso verbal. Es prelingüístico. El underground elude la definición verbal y permite una definición sentimental y sociológica que remite al concepto de tribu. La emoción, sin embargo, es la tendencia emotiva no codificada socialmente, que se aplica (de nuevo) al underground, ya que busca salir del molde y perseguir una codificación nueva. De esta forma, uno podría encontrarse en la situación de comprender este diálogo: ¿Cómo te sientes? Me siento punk. Este estado del sentimiento (Williams, 1980: 147) se representa de una manera retrospectiva proyectiva en tanto que artefacto cultural. De nuevo, volvemos al cuerpo, pero esta vez desde su concepto de vulnerabilidad. Como hemos visto, la ciudad, la nueva identidad y la inmersión en un nuevo ambiente tribal o amistoso nos marca tanto emocional y afectivamente (visceralmente) a través del uso y las modificaciones que hacemos de nuestro cuerpo. Un cuerpo que, fuera de su área tribal, se mantiene vulnerable a las miradas de los «normales» (Becker). Un cuerpo que busca construir un espacio temporalmente autónomo.

En la música, esta retrospectiva proyectiva, esta emocionalidad y vulnerabilidad se construye, de manera primitiva e instintiva en su relación con la música y la sociedad. Es decir, en el baile. En el caso del flamenco es el propio baile el que cosifica la música en expresiones kinestésicas y representativas culturalmente. Sin embargo, el baile también es un elemento social que sirve para conectar a los individuos desde su propia individualidad (aunque efímera en cuanto acaban los compases). La investigadora Silvia Citro se centra en el estudio de otro tipo de baile en El análisis del cuerpo en contextos festivo rituales: el caso del pogo $0^{6}$ :

6 Baile que encuentra su origen en el género punk. Consiste en bailar en el propio lugar, dando saltos, o bien acompañar estos de patadas y empujones al resto de bailarines sin un objetivo 
Si bien los comportamientos kinésicos en este tipo de prácticas pueden ser generados en torno a ciertas representaciones sociales, así como pueden inducir diversos patrones representacionales, ellos, en sí mismos, no siempre pueden ser tratados como representaciones, y, sobre todo, provocan cambios en las experiencias de los sujetos en movimiento. (Citro, 2001: 1)

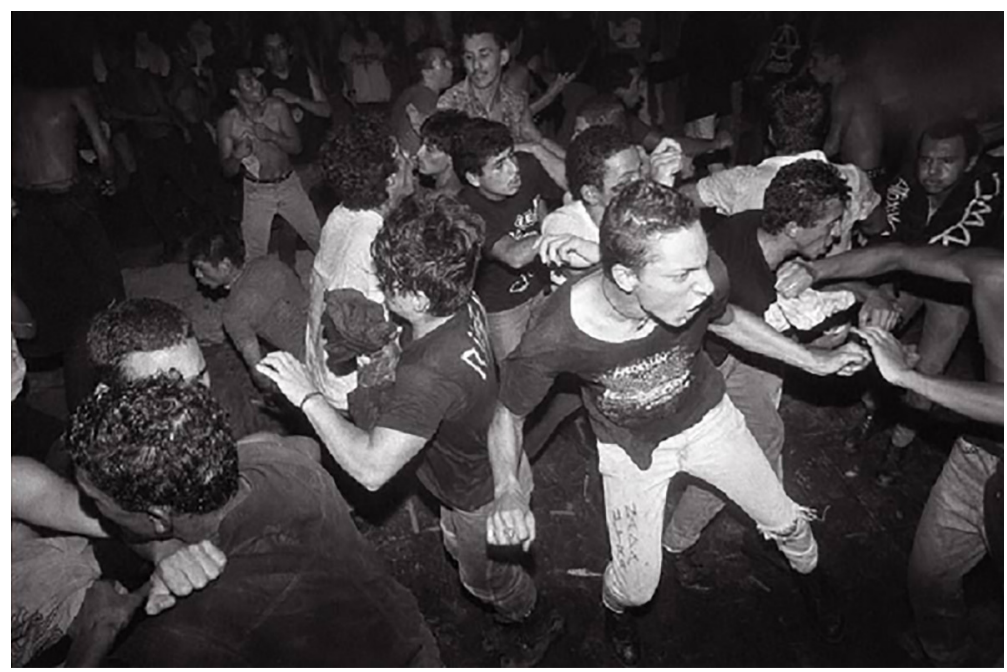

Figura 1. Danza de un pogo.

Fuente: Gertjan Bartelsman (1990).

Estas palabras permiten continuar estableciendo un paralelismo entre el flamenco y el pogo, puesto que, aunque completamente opuestos en su ejecución, predisponen para la consecución de una actitud similar: el desahogo y la liberación del espíritu o los instintos desde un punto de fuga totalmente físico. Es esta fuga emocional, este momento de relajación del cuerpo, el que interesa a la hora de relacionar el baile con la cultu-

violento. Se trata de arrastrar al resto de asistentes a una danza violenta común en el que dejar salir toda la visceralidad del cuerpo. 
ra underground; sobre todo, dentro de un contexto de dominio hegemónico. En concreto, el Franquismo luchó su particular cruzada contra el baile a lo largo de la posguerra e incluso alcanzando ya los años 60 . El baile era visto como una tentación para las mentes (y los cuerpos) jóvenes. La danza predispone, según las alarmas de las Iglesias y del propio Régimen, a la consecución de los pecados más terribles, así como a la pérdida de la honradez de las mujeres (Regueillet, 2004: 1034). Bailar, entonces, se convierte en indispensable para ir a la contra del Sistema.

Volviendo al texto de Citro acerca del pogo, podemos observar una descripción de los sentimientos y emociones que embargan a los participantes de este baile. Lo que obtienen estos jóvenes a través del desahogo corporal puede retrotraer a la protesta que lleva implícita este tipo de baile (al estar ligado al género punk), tanto como a las emociones generales que se producen a la hora de ejercer un ejercicio físico placentero. Salir de allí, huir de las circunstancias. Toda una protesta implícita, si trasladamos estos sentimientos a un contexto de posguerra o de represión:

...La idea de que algunos géneros predisponen a ciertas actitudes emocionales más que otros, en el caso de los géneros discursivos y musicales, goza en general de bastante consenso, a nivel de los géneros corporales pienso que sucede algo similar, sobre todo en las prácticas festivo-rituales que favorecen una profunda interrelación entre las manifestaciones estéticas kinésicas, discursivas y musicales. En relación a esta dimensión emotiva para el caso del pogo, en las diferentes charlas mantenidas con sus practicantes, este baile aparecía asociado reiteradamente a los significantes de «descarga», «liberación», «catalización» o con el «sacarse la rabia, la bronca», y destacaban lo que llaman la «buena onda del pogo» en el hecho de que por ejemplo «si te caes te levantan». El pogo era definido como «joda», «diversión», como algo que «te hace rebién» y era relacionado fundamentalmente al placen». (2001: 13) 
Así, Citro nos lleva a experimentar de manera teórica el sentimiento de individualidad versus comunión colectiva del baile del pogo: un espacio temporalmente autónomo que, a base de miradas, gritos y empujones con el resto de la concurrencia, produce una comunicación social dentro de un contexto simbólico que puede desarrollarse tan solo en determinados espacios.

Este tipo de actividades pseudorrituales y de actitudes fuera de la normalidad y los ambientes diurnos son desarrollados, como se ha expuesto, dentro de las grandes urbes. Sin embargo, hacen falta espacios específicos para el desarrollo de estos bailes, músicas y conductas. Nos referimos a las salas de música. Un espacio tanto de libertad como de confinamiento de los considerados anormales o desviados de la sociedad diurna. Algo que podría relacionarse incluso con los espacios de confinamiento estudiados por Foucault, y que Jordi Planella resume en su estudio Corpografias: dar la palabra al cuerpo:

En este sentido, hemos puesto en juego las epistemologías del cuerpo en las ciencias sociales (Le Breton y Turner), los cuerpos de-formados, los cuerpos retorcidos en la teoría queer ${ }^{7}$ y la reconstrucción del cuerpo en las sociedades complejas. Todo ello con la finalidad de poderlo situar en la dimensión Leib (cuerpo cultural) y más allá de la dimensión Körper (cuerpo anatómico). (Ribera, 2006: 13)

En este sentido, lo que realmente interesa a Planella y viene a colación de esta investigación son las formas de control de los sujetos mediante su corporalidad. Foucault estudia las cárceles, los psiquiátricos, lugares de confinamiento que separan a la sociedad normativa de la desviada, ya sea por una cuestión de marginalidad o delincuencia (las cárceles), o por haberse salido de la norma

7 Término con el que se define a las personas que no se identifican con un género binario o un sistema establecido. La teoría queer niega la sexualidad hombre-mujer. 
social establecida, (psiquiátricos, donde hasta hace bien poco, en España, todavía recaen en el periodo citado de la dictadura franquista los homosexuales, mujeres indeseadas por su familia, o simplemente sin lazos familiares, transexuales, etc.) (Huard, 2014: 68).

Estas personas divergentes encuentran, fuera de estos lugares de reclusión no deseada, otros espacios creados por ellos mismos en los que mantenerse al margen de la normalidad y una autoridad que, con la excusa de alimentar esta normalidad y este orden social a salvo, es capaz de castigarlos, castrarlos y torturarlos. Se trata de las salas de conciertos, lugares abiertos al público - es decir, no son asociaciones secretas, clubs o cualquier otro tipo de local cerrado tan solo a aquellos que lo conocen-, en el que los que se encuentran cometiendo el acto de desviación básico de salirse de la norma establecida por el Régimen, pueden encontrarse. No son cárceles, pero les mantienen separados de la sociedad diurna. Regresemos a las palabras de Planella para comprender mejor el planteamiento de Foucault a través del cual se establece el de esta investigación:

Para Foucault el cuerpo es un espacio de investidura del poder, ya que se concibe como dominación, como lugar de control y opresión. Existirían dos formas básicas de control corporal: las disciplinas (ejercidas directamente sobre los cuerpos) y las regulaciones de la población (a través de los sistemas institucionales de organización de grupos y personas). Mediante el estudio de diferentes instituciones (la prisión, los internados, la escuela, el cuartel, los psiquiátricos, los hospitales, los conventos, etc.), estudia la forma en que estas ejercen el control de los cuerpos y de las personas que los «poseen». Hará lo mismo analizando, con los tres tomos de la Histoire de la sexualité, cómo las prácticas sexuales (y, por lo tanto, corporales) son construidas socioculturalmente. Se trataba de estudiar todo el conjunto de técnicas e instituciones que querían medir, supervisar y corregir los sujetos considerados anormales, con la intención de alejar- 
los de la población para evitar contagios y transformaciones sociales no deseadas. (2006: 17)

Sin embargo, para realizar un estudio sobre estos espacios, primero se ha de establecer la diferencia entre underground $\mathrm{y}$ contracultural, con el fin de seleccionar los espacios que más se ajusten al estudio. Según explica Roberto Goycoolea Prado, hay que «[...] conocer la localización urbana y las características de los espacios diseñados para una actividad social específica contribuye a comprender su papel en la ciudad y las relaciones establecidas con las demás actividades y estamentos sociales» (Prado, 2007: 13). Algo que supera el límite de este texto, pero que nos permite alcanzar su conclusión a la hora de relacionar, por un lado, la importancia de la fisicidad en un contexto contracultural y, por otro, el castigo de esta corporalidad mediante la represión y, por tanto, la búsqueda de espacios divergentes por parte de esta contracultura para el desarrollo de esta «investidura de poden» (Foucault) que otorga el uso del propio cuerpo para el simple regocijo.

\section{Conclusiones: el baile como acto de poder dentro de la contracultura}

Hasta ahora, se han observado en este texto conceptos que bien podrían rozar un ámbito filosófico más que social. Se ha hablado del anonimato, del estado social de pertenencia y del reencuentro con la corporalidad. Efectivamente, se puede llegar a afirmar que uno de los pasos tribales más fundamentales a la hora de empezar a formar parte de una determinada contracultura es la recuperación del cuerpo como elemento identitario y de poder. Es decir, empezar a considerar al propio cuerpo como un espacio filosófico a la par que físico. Un cuerpo que se piensa y se modifica a la par que se siente y se disfruta. Por ello, durante el texto se ha citado a Foucault o Maffesoli, tratando de buscar un enfoque que trascendiera los estudios culturales. 
En este sentido, se ha podido observar también cómo el cuerpo se establece como lugar de encuentro con los otros, estableciéndose «comunidades emocionales» a través de la «fisicalidad de la experiencia» en un «reencuentro con la corporalidad» que se realiza a través de la diversión, el placer y el hedonismo. Es en este reencuentro lúdico donde entra en juego el papel del baile, en tanto que conector que permite establecer un «estado de pertenencia y afecto» a la par que un «estado de independencia temporal» entre el grupo. Los danzantes renuncian a parte de su espacio físico personal en virtud de un espacio colectivo, creando un afecto que se establece a través de la música y el ritmo.

El texto de Silvia Citro alrededor del baile del pogo nos permite encontrar, también, el valor social que adquiere el baile en contextos contraculturales en los que la interacción con el prójimo en un estado de desinhibición y visceralidad permite sacar a la luz la personalidad elegida. Esa máscara social construida en torno a las experiencias, que empuja a los «desviados sociales» a buscar otro tipo de afectos y relaciones, fuera de la sociedad normativa.

También se ha indagado en el papel que guarda la urbe como escenario ineludible para la creación de personalidades «al margen», en el que el anonimato es posible y deseable, y en el que se pueden encontrar espacios de automarginación en los que llevar a cabo actos que no serían comprendidos dentro de la sociedad bienpensante.

Es por esto que la prohibición —o la recomendación de restricción - del baile acaecida a raíz de la crisis sanitaria puede ser comprendida también como un acto de censura del desarrollo de la cultura underground, ya que frena uno de los actos que más une a este tipo de subculturas, a la par que restringe también el deseado contacto social entre seres semejantes. Se trata de un acto que, como se mencionaba previamente, resulta trascenden- 
te desde un punto tanto social como filosófico, ya que nos lleva a frenar el lenguaje no-verbal y social que supone el uso del cuerpo como desfogue, contacto y medio de afecto con los otros. «El cuerpo es un espacio de investidura de poder», leímos a Foucault en este mismo texto. Cabe concluir, entonces, que el hecho de que se nos despoje del cuerpo como objeto lúdico también supone renunciar a parte de nuestro poder social y de contacto de los unos con los otros. En un contexto de crisis sanitaria, el uso del cuerpo se ve limitado al ejercicio económico y de consumo: ir al supermercado, trabajar, consumir. El ocio se ve restringido a una parcela que ha de ser desarrollada, preferiblemente, en soledad: se fomenta el consumo de plataformas online, se fomenta el acceso a la cultura a través de las pantallas. Para ello, se cierran los espacios ya citados como de seguridad afectiva (salas de conciertos, bailes, discotecas). Mientras, el necesario contacto social también está dirigido a lo digital. La corporalidad social se ve abandonada, dejando de lado también el «estado emocional de pertenencia y afecto» y la máxima de Le Breton: «los afectos son reglas que nos transgreden».

Es necesario volver a repetir que no es el objeto de este texto juzgar la idoneidad de las restricciones establecidas en la crisis sanitaria; tan solo recordar (y reivindicar, en cierto modo) el hedonismo como parte necesaria del desarrollo del ser humano en sociedad. En este momento nuestra sociedad se enfrenta a una grave enfermedad física; pero no se debería obviar a la diversión, la música y el baile como medicinas necesarias para el espíritu. De lo contrario, nos encontraremos al final de esta crisis con una pandemia superada por una sociedad enferma en sus más profundos afectos. 


\section{REFERENCIAS BIBLIOGRÁFICAS}

Arce Cortés, T. (2008). «Subcultura, contracultura, tribus urbanas y culturas juveniles: ¿homogenización o diferenciación?». Revista argentina de sociología, 6(11), pp. 257-271.

Becker, H. (2010). Outsiders Hacia una sociología de la desviación. Buenos Aires: Siglo Veintiuno Editores.

Citro, S. (2000). «El análisis del cuerpo en contextos festivo-rituales: el caso del pogo». Cuadernos de Antropología Social, 12, pp. 225-242.

FeIXA, C. (1994). «De las bandas a las culturas juveniles». Estudios sobre las culturas contemporáneas, 15.

Ganter Solís, R. (2005). «Cuerpos suspendido: cartografías e imaginarios de la piel en jóvenes urbanos». Polis. Revista Latinoamericana, 11.

HuArd, G. (2014). «Los antisociales». En Historia de la homosexualidad en Barcelona y París (1945-1975). Madrid: Marcial Pons.

Le Breton, D. (2009). Las pasiones ordinarias: antropología de las emociones. Buenos Aires: Nueva Visión.

LuTz, B. (2006). «El cuerpo: sus usos y representaciones en la modernidad». Convergencia. Revista de Ciencias Sociales, 41.

Maffesoli, M. (1990). El tiempo de las tribus. Barcelona: Icaría.

Marcus, G. (2005). Rastros de carmin: una historia secreta del siglo XX. Madrid: Anagrama.

Naharro, F. G. (2012). «Cultura, subcultura, contracultura: "Movida" y cambio social (1975-1985)». Coetánea: III Congreso Internacional de Historia de Nuestro Tiempo. Universidad de La Rioja, pp. 301-310.

Prado, R. G. (2007). «Papel y significación urbana de los espacios para la música en la ciudad occidental». Política y sociedad, 44(3), pp. 13-38. 
Regueillet, A. G. (2004). «Norma sexual y comportamientos cotidianos en los diez primeros años del Franquismo: noviazgo y sexualidad». Hispania, 64(218), pp. 1027-1042.

Williams, R. (1980), Marxismo y literatura. Barcelona: Editorial Península. 